Mark Payne, "What's an Ark?," Relegere: Studies in Religion and Reception 7, nos. I-2 (20I 8): 73-9I.

(c) BY-NC-ND This work is licensed under a Creative Commons Attribution Non-Commercial No Derivatives 3.0 License.

Relegere: Studies in Religion and Reception is an independent, open-access academic journal dedicated to the promotion and dissemination of innovative research in reception history, broadly conceived, within and across religious traditions.

www.relegere.org

ISSN I I 79-723 I 


\section{Mark Payne}

\section{What's an Ark?}

An organism threatened with extinction is entrusted to safe storage in the hope that the conditions it needs to survive might one day be available to it again. The ark of Genesis has been widely used to imagine conservation projects of this kind. My paper circumscribes ark building as a conservation activity with other instances of ark building in contemporary culture, from Lars von Trier's Melancholia to Lee Scratch Perry's Black Ark. What is at stake when we decide that some form of life is, or is not, worthy of being set on its way to a life to come? HE IDEA of the ark is widely used in conservation biology to name projects
in which an organism threatened with extinction, or its genetic material, is entrusted to some form of safe storage in the hope that the conditions it needs to survive might once again be at hand in some as yet undetermined future. On the face of it, this terminology is hardly worth interrogating. What else would you call such a project but an ark? The Genesis story is so obvious an image for the work of organismic transport it can hardly be avoided. But perhaps the obvious is what is most in need of interrogation. Ark building is everywhere, even when it is not named as such, and its distinctive relationship between melancholy and manual labor reveals the presence of arks in

Mark Payne is Professor in the Department of Classics and in the Committee on Social Thought at the University of Chicago. 
some surprising places. I will therefore be eclectic, even at the risk of being superficial. For it is by identifying as many kinds of ark as possible that we will get the most complete picture of ark building as a form of relationality with a precarious future — of everything that is at stake when we decide that there had better be an ark for something that ought to go inside it.

\section{Noah's Ark}

The English word "ark" comes from the Latin arca. An arca is a container for what you want to save, and for what you want to get rid of. In the Oxford Latin Dictionary, the first meaning of arca is "money box." The second is "coffin," especially a pauper's coffin. Arca is a noun formed from the verb arceo, which means to ward something off, or to keep something at a distance. An arca is thus the thing with which, or by which, you establish the proper degree of proximity and intimacy with respect to its contents, whether this is treasure or a corpse. The Greek translation of Genesis uses the colorless $\kappa ı \beta \omega \tau \dot{s} \varsigma$ for Noah's vessel, instead of the more obvious $\lambda \dot{\alpha} p v \alpha \xi$, which is exactly parallel to the Latin arca. In Liddell and Scott's Greek-English Lexicon, the first meaning of $\lambda \dot{\alpha} \rho \nu \alpha \xi$ is "coffer, box, chest, e.g. for household stores." The second is "cinerary urn or coffin," a usage that includes "an ark in which children were exposed." Perhaps the Greek translators were inspired to avoid the doubts about storage or disposal that $\lambda \dot{\alpha} \rho \nu \alpha \xi$ would have raised, but the Latin term that English has inherited is an excellent example of what William Empson, in Seven Types of Ambiguity, calls the seventh type of ambiguity. This, the most ambiguous ambiguity that can be conceived, occurs when "the two meanings of the word, the two values of the ambiguity, are the two meanings defined by the context, so that the total effect is to show a fundamental division in the writer's mind." 1

Arks formalize our ways of relating to their contents. Faced with what is precious or loathsome, we require proper distance to be established and maintained, and this is the task of its receptacle, the object that secures its passage through time. But if an ark is both what is used to preserve something precious, and what is used to dispose of something loathsome, how are we to know which usage is operative in a given context, and that we are not in the presence of a fundamental division in the ark builder's mind, of the kind that Empson imagines? The answer would seem to be: context. But how much

${ }^{1}$ William Empson, Seven Types of Ambiguity (New York: New Directions, I947), 192. 
does the context of the Genesis story tell us? God observes that life on Earth is evil and does not deserve to survive:

God saw that the wickedness of man was great in the earth, and that every imagination of the thoughts of his heart was only evil continually. And it repented the Lord that he had made man on the earth, and it grieved him at his heart. And the Lord said, I will destroy man whom I have created from the face of the earth; both man, and beast, and the creeping thing, and the fowls of the air; for it repenteth me that I have made them. But Noah found grace in the eyes of the Lord. (Gen 6.5-8)

Man's evil for God is total and so is the grief that it causes him. The only relief from His melancholy is the prospect of humankind's imminent destruction. Any division in God's mind hinges on a single individual. What is to be destroyed is humanity in its entirety. What is to be preserved is Noah and his family alone. That the rest of humankind is not to be mourned is evident; this is the point of the story. But what of the remainder of the living - all the nonhuman life that does not make it onto the ark, both the individual animals that are not called from the kinds of animals that are to be preserved, and whatever other kinds of animals perish in their entirety because they are not part of the project of Noah's survival?

This is not an occasion for manna. Life will have to be sustained by Noah, his family, and the transported animals once they exit the ark. This much we know. But is saving the animals merely an entailment of the survival project to which God commits himself for Noah's sake? Are the rest of the living not to be mourned, because nonhuman life exists only to sustain human life? Is it only because Noah and his family have to be kept alive as humankind's regenerative remainder that the other animals have to be borne along with them-put up on board and put up with thereafter? The rest of life is affectively inert as the background to the drama of human and divine agents in the story so far, but perhaps a life of differently ordered human-animal relations belongs to its vision of the future, the new dispensation that lies on the other side of the flood. Should we credit the storyteller with allowing us to imagine another life to come, in which humans and animals partner up in a different form of life than the one they have left behind?

This would surely be the saddest story of all, since any such utopian possibilities have long since dissipated in the present of the moment of narration, 
a present of predation and domestication that reproduces the pre-flood conditions, at least as far as nonhuman life is concerned. Noah's trans-species hospitality, if that is what he shows, has apparently been lost on his descendants, and if a state of constant catastrophe is the condition of such hospitality, ${ }^{2}$ this would surely be the best proof available of the justice of God's indictment of humankind.

\section{Cosby's Ark}

Back when Bill Cosby was mostly known as a comedian, he used to write funny sketches like this one:

You see Noah was in his rec room, sawing away. He was making a few things for the home there. He was a good carpenter.

Vroopa, vroopa, vroopa, vroopa.

Noah!

Somebody call?

Vroopa, vroopa, vroopa.

Noah!

Who is that?

It's the Lord, Noah.

Right! Where are ya? What you want? I've been good.

I want you to build an Ark.

Right! What's an Ark?

Get some wood build it 300 cubits by 80 cubits by 40 cubits.

Right! What's a cubit?

Let's see, a cubit. I used to know what a cubit was. Well don't worry about that Noah. When you get that done go out into the world and collect all of the animals in the world by twos, male and female, and put them into the ark.

Right! Who is this really?

Bill Cosby's Noah is a man who works as much as he possibly can with his hands, and as little as he possibly can with his head. He thinks only when he has to, and when he is forced to think outside the box he has been tasked with making, it is to imagine himself on the receiving end of a cosmic prank.

${ }^{2}$ Kate Rigby, "Noah's Ark Revisited: (Counter-) Utopianism and (Eco-) Catastrophe," Arena 3I (2008): 163-78. 
God likes this about him, and when He tells him about his plans for the imminent destruction of humanity, He does so in a somewhat unconvincing robot voice, a poor impersonation of the divine machinery that Noah thinks is playing tricks on him.

God's fake robot voice competes with Noah's saw sounds: Vroopa, vroopa, vroopa, vroopa. The saw is funnier than the word-even the words of a fake divine robot-but it is also true that it is better to spend your time making hand noises than mouth noises. God chooses Noah because he can be counted on to approach the end of the world by keeping on doing what he does, instead of thinking it through. The combination of handicrafts and impossibility makes ark building what it is.

Noah the ark builder is not inclined to mourn the imminent destruction of life. When his neighbor asks him what the wood structure in his driveway is for, he replies "How long can you tread water?", and he follows up this knowing remark with a loud and sustained "Ha ha ha ha ha." God will gleefully echo Noah's remark, and his laugh, back to him, when he begins to baulk at the magnitude of the task he has taken on.

Cosby's sketch invites questions about the genre of the end of the world. The philosopher Plotinus, in "Against the Gnostics," mocks his adversaries for shuddering over a cosmology that reeks of "the fearful stuff of tragedy" (Ennead 2.9.1 3). This is not to show that the Gnostics' eschatological endgame is misconceived, for Plotinus's is very similar, only that they have got the genre wrong. Instead of weeping over the imprisonment of divine substance in a material universe, they could, for example, laugh about it instead. For what could be funnier, from a certain point of view, than the rat of soul trapped in the maze of matter, and not being able to find its way out until the end of the world? Whatever the genre of God's pronouncement in Genesis, lament is evidently not the correct response to the spectacle of humanity's imminent inundation, as Cosby's Noah imagines it.

\section{Justine's Ark}

Lars von Trier's Melancholia is a film about the end of the world. A planet by the name of Melancholia enters Earth's solar system from behind the sun. It draws ever closer to the earth, but then appears to be passing it by, only to return and crash into it. The film looks at how different people respond to the impending catastrophe and, in particular, the contrasting responses of two sisters: Justine, whose failed wedding occupies the first half of the film, 
and Claire, who hosts the wedding in her country house, which is where the two sisters subsequently await Melancholia's arrival. Justine's co-workers play their part in the wedding drama, but the second half is just Justine, Claire, and her family - her husband, her young son, and their horses, who await the end of the world with varying degrees of open-mindedness and clearsightedness.

The husband is disposed of early in the proceedings. Once he realizes that the scientists have got it wrong, and Melancholia won't be the aesthetically pleasing and scientifically informative fly-by he had been promised, he kills himself with the anti-depressants that Claire had put aside to alleviate her own anxiety. Claire's approach is to try to do the right thing. She covers up her husband's body so that no one will discover it, and makes it look like he has ridden off in search of help. She then tries to escape with her son, and when this plan fails she suggests to Justine that they await the advent of Melancholia with a glass of wine on the garden terrace.

Justine thinks this is a terrible idea. Justine is persistently depressed. She has already terminated her marriage and her career, so it is not a huge surprise when she tells Claire that life on Earth is evil and no one will miss it. The film's surprise ending, then, is that in the moments before Melancholia's arrival, it is Justine who takes charge of the end of life for herself, for Claire, and for Claire's son. She who had seemed to be beyond care becomes an accomplished caregiver. She had promised Claire's son that they would build a magic cave in the course of her visit, and she now makes good on this promise. They gather sticks from the woods together, which the child sharpens with a pocketknife, and they then fit these sticks together to make a tipi frame. The film ends with Justine, Claire, and her son sitting inside the uncovered tipi frame as Melancholia enters the earth's atmosphere, consuming everything in its path.

Claire's mourning is pointless. Claire, as usual, wants to do the right thing, but there is no sense in mourning when the destruction of what is to be mourned will be absolute and complete. There will be no more world in which her mourning could be consequential, to herself, or to anyone else. But why does Justine, the clear-sighted melancholic, build a tipi? Why not just let events take their course? The tipi's uselessness as a shelter is marked by the fact that, unlike a real tipi, its frame is not covered. We watch Justine, Claire, and her son sitting inside it as Melancholia approaches. They close their eyes, but this is more a gesture of solidarity than self-defense, or even defensiveness. They see Melancholia, and it sees them, for the planet is in- 
vested with a brooding animacy by the Liebestod from Wagner's Tristan and Isolde that accompanies its every move.

Justine's tipi of twigs is a kind of ark. Justine's project is to transfer the work of interiority - the work of mourning to which Noah is immune-to the work of the hands. Justine and Claire's son build the tipi as a handicraft, a hunter-gatherer project, in contrast to the technoscience of Claire's husband, whose emblem is the telescope. His technoscience offers no affordances for continuing to live in a doomed world once its lack of practical utility is exposed. Justine manualizes the project of accommodation to the world without hoping that she is anything other than doomed. She moves conceptual making good into the work of the hands, and it is this insistence on building, making, and doing in all its manifest uselessness that makes what she does ark-building: the work of living on without the expectation that the world can be saved or made good.

In Melancholia, the cosmos comes too close, in the form of a colossal piece of hostile matter that can't be warded off, and Justine's ark crystallizes ambiguity about the earth as the site where life is stored. Her ark is a miniature of the earth itself as the receptacle of precarious life, but for Justine herself, life is better off dead. God's point in Genesis that human evil doesn't miss a beat is nicely captured in Melancholia in a scene between Justine and a junior employee of her former boss. The young man has been assigned to track Justine on her wedding night in the hope of capturing a tagline for an advertising campaign to which she has been assigned. By abusing her boss to his face, Justine effectively terminates her employment, but she also has sex with the young man, who she seems to pity. His insight into the situation is that she now needs a job and a husband, and he proposes that they get to know one another, in both a commercial and a biblical sense.

Melancholia torques the affect of the sci-fi "when worlds collide" subgenre towards a kind of comedy — cosmicomedy, we might call it—in Justine's refusal to mourn the imminent spectacle of the world's destruction by fire. The phenomenon to which the end of the film gives witness is what the ancient Stoics called ekpyrosis: the world's inevitable consummation and self-fulfillment in the form of a fireball, to which philosophy's response is the genre of the consolatio, Stoicism's signature form. It is a consolation that changes nothing and helps very little. Just the opposite of a maximal solution, it offers becoming at peace with the inevitable as the little that philosophy has to offer-an ark of words, like Justine's ark of twigs. If mourning enacts a kind of radical hope, hope down to the wire, or hope against hope, in its 
elegiac effusions about life about to be lost, consolation refuses this hope, accepting the inevitability of the catastrophe as what has to be faced.

Justine's observation that life on Earth is evil and does not deserve to survive is of a piece with God's judgment in Genesis, and no gestures of hospitality towards nonhuman life follow from her ark building, even though the texture of her ark is as open to the world as a human structure can be. Is Justine thereby included in her own judgment of life on Earth? Presumably this is not a conclusion that she herself would resist. Other life appears in Melancholia as the perspective of individuals of a single kind, the family's horses, who are ridden for pleasure by Justine and her sister. Indeed, Justine herself beats Abraham, her favorite horse, relentlessly when he refuses to do her bidding and cross a bridge, as Claire will later abandon a golfcart for the same failing at this very juncture. Abraham's death at Justine's hands is recapitulated aesthetically in the film's imagistic overture, where it appears ahead of the events of the narrative. His riderless collapse is the choreography of a superhuman aesthetic affect that, like the Liebestod that accompanies it, belongs to the film, but not to its human protagonists.

\section{Julia Kristeva's Ark}

What happens, then, when ark building becomes the narrative in which the fate of the other animals is imagined? How do animals look out from the arks of technoscience when they, not us, are the primary objects of attention? Virtually every effort to preserve the existence of a life form threatened with extinction in the present by sending it forward into a dimly imagined future invokes the idea of the ark. In Resurrection Science, M. R. O'Connor describes the Amphibian Ark, the Frozen Ark, and the Ark Corporation, a variety of initiatives for projecting biodiversity into the future by preserving genetic material in the present. ${ }^{3}$ Thom van Dooren has explored a variety of others with a remarkable combination of precision, empathy, and critical distance. ${ }^{4}$ And presumably there will be yet other arks too, an ever increasing proliferation of vessels to transport what no longer has any home on the planet on which and for which its life evolved towards a future Earth that might one day be its home once again.

${ }^{3}$ M. R. O'Connor, Resurrection Science: Conservation, De-Extinction, and the Precarious Future of Wild Things (New York: St. Martin's Press, 20 I 5), 35, I4I, I89.

${ }^{4}$ Thom van Dooren, Flight Ways: Life and Loss at the Edge of Extinction (New York: Columbia University Press, 20 I4). 
"Resurrection science" is a contradiction in genre. "Resurrection" belongs to the discourse of eschatology at its most literal. "Science" names the condition of disenchantment from such hopes. Is this, then, an ambiguity in Empson's seventh sense, the final revelation of a divided mind going full speed ahead but unable to make any headway with the task at hand? Before we can answer this question, we need to take a step back, and think about metaphor at a more basic level. Empson invokes metaphor as his first kind of ambiguity in so far as it involves an undermining of the simple presence of the particular entity on which it operates: "One thing is said to be like another, and they have several different properties in virtue of which they are alike." 5 Thinking of $\mathrm{x}$ in terms of $\mathrm{y}$ already enacts, if not a divided mind, then at least a mind that is not sure what to do with itself in the face of some particular thing. Imaginative work is called for to make the thing pass over from the challenge of its merely being there into the non-irreducibility of a thing thought of as other than itself.

Metaphor is the first stop on the journey of derealization that Rilke describes in the Ninth Duino Elegy:

Erde, ist es nicht dies, was du willst: unsichtbar

in uns erstehn?-Ist es dein Traum nicht, einmal unsichtbar zu sein? - Erde! unsichtbar! Was, wenn Verwandlung nicht, ist dein drängender Auftrag?

Earth, is it not this that you want: to rise up in us invisible? Is it not your dream to be invisible some day?-Earth! Invisible one! What, if not transformation, is your urgent injunction?

According to this way of thinking, the things of the earth want to be disposed of, not preserved. In a recursive enactment of the process it imagines, Rilke's poem envisages the ambiguity we experience in the presence of the things of the earth as actually proper to the things themselves. We enact their own will to disappearance on their behalf, by making them disappear into the works of human culture. Our metabolization of them imagined as their own wish for transubstantiation expresses our ambiguity about their presence. We want them, but not here and not now. We want them in art so we can be done with being with them in life.

${ }^{5}$ Empson, Seven Types of Ambiguity, 2. 
In Black Sun, Julia Kristeva stresses the transit into language as what is denied to the melancholic person in their attachment to the thing itself: "To transpose corresponds to the Greek metaphorein, to transport; language is, from the start, a translation, but on a level that is heterogeneous to the one where affective loss, renunciation, or the break takes place." The melancholic is unambiguous, of undivided mind, and rejects the transposition that is the fate of the speaking being, the ceaseless shuttling of things into words so as to be done with being with them. The weight of the thing prevails, preventing its embarkation. The craft of language cannot get underway, and the melancholic's attachment ends in asymbolia unless their excess affect can produce new languages: "strange concatenations, idiolects, poetics."

Noah's Ark makes a brief appearance in Black Sun, precisely as a metaphor — a kind of ideal metaphor, or metaphor of metaphor. Kristeva is discussing Gérard de Nerval's sonnet of melancholy, "El Desdichado," and she notes its salvific function for the poet amid the onset of depression:

In August the symptoms showed up again: there he was, like a threatened archaeologist, visiting the osteology wing of the Jardin des Plantes; convinced, in the rain, that he was witnessing the Flood. Graves, skeletons, the irruptions of death indeed continually haunted him. Within such a context, "El Desdichado" was his Noah's Ark. Albeit a temporary one, it nevertheless secured him a fluid, enigmatic, spellbinding identity. Orpheus, once again, retained victory over the Black Prince. ${ }^{7}$

The figure is only partially motivated by the context, but Kristeva, who devotes a chapter to the poem, is not being flippant. Ark building is a figure of melancholy because it captures in a single image the salvific potential of the poetic work on which survival is staked. In Melancholia's Dog, Alice Kuzniar picks out Kristeva's unique feeling for the relationship between language's silences and its "exuberant compensations," noting Kristeva's peculiar insistence that, for the melancholic, poetic language is "a compensatory pleasure that is counterpoised to privation and soothes with the creation of loveliness." 8 But the ark that is floated on the tears of Orpheus will not travel far.

${ }^{6}$ Julia Kristeva, Black Sun: Depression and Melancholia (New York: Columbia University Press, I989), 4I-42.

${ }^{7}$ Ibid., I 44.

${ }^{8}$ Alice Kuzniar, Melancholia's Dog: Reflections on Our Animal Kinship (Chicago: University of Chicago Press, 2006), 36-37. 
The head that is remade in the act of making slowly subsides into the waters. Like Justine's ark of twigs, it is not a resistant structure. The magic fades, and what was salvaged morphs imperceptibly into the sad spectacle of an ordered remnant, an unenchanted remainder.

\section{Shel Silverstein's Ark}

It is just such a fading of creation's enchantment that is staged in Shel Silverstein's ark poem, "The Unicorn”:

A long time ago, when the earth was green

And there was more kinds of animals than you've ever seen, And they run around free while the world was bein' born, And the lovliest of all was the Unicorn.

Unfortunately, when the rain begins, the unicorns are too busy being free to heed the danger. They are left behind by the ark and drown in the flood, so that while in the future to which the other animals are destined you will see "catsandratsandelephants," it is just as certain that "you're never gonna see no Unicorn." The Unicorn is a capital letter animal, the others a homogenous lump of being that reflects their instrumentalization and conformity with God's plan. The poem stages the fading of creation as the before and after of an enchanted past and a disenchanted present that no wishing can bridge.

Silverstein's poem was set to music by the (Canadian) folk band Irish Rovers. For all its will to cheery singalong affect, their version has a sadness that translates the child's natural affinity for animal identification, as an alternative to the tedium of adult human life, ${ }^{9}$ into melancholic spectacle, so that the child can contemplate losing the very possibility of such identification as a condition of its growing old, like the world. The poem is relentless in its imagining of the moment of loss as an extended farewell. The unicorns actually cry, and you watch them cry. Their childishness is your childishness, viewed from the outside, and singing adds the final touch to this strange concatenation, as if Orpheus were seeing the tears streaming down his own sinking, singing head:

${ }^{9}$ Gilles Deleuze and Félix Guattari, Kafka: Toward a Minor Literature (Minneapolis: University of Minnesota Press, I986), I 2: "To become a beetle, to become a dog, to become an ape ... rather than lowering one's head and remaining a bureaucrat, inspector, judge, or judged. All children build or feel these sorts of escapes, these acts of becoming-animal." 
Then the ark started movin', and it drifted with the tide, And the Unicorns looked up from the rock and cried.

And the water come up and sort of floated them awayThat's why you've never seen a Unicorn to this day.

\section{Ken Ham's Ark}

In Shel Silverstein's poem and its musical setting, Noah's ark is a threshold story for the reflective apprehension of childhood by children. The fading of creation is the fading of childhood projected onto animals. The linkage between Noah's Ark and childhood has come to seem familiar because of the proliferation of ark toys for children, and it is this linkage that the newly opened Ark Encounter in Williamstown, Kentucky sets out to disrupt.

The Ark Encounter is a recreation of Noah's Ark by the Australian fundamentalist Ken Ham. It is built according to Biblical specifications. At 5 Io feet long, 85 feet wide, and 5 I feet high, it is the largest timber-frame structure in the world. It consists of three decks, accessed through a ground level entrance, and within these decks, exhibits are displayed according to a thematic arrangement: on Deck I, "The Flood Begins"; on Deck 2, "Technology on the Ark"; on Deck 3, "After the Flood."

Much of the wall space on the exhibition decks is given over to signage with arguments for creationism versus evolution, but the Ark Encounter is meant to convince as much by the experience it offers as by the arguments it displays. The visitors map proclaims: "Bigger than Imagination: A lifesized Noah's Ark Experience." Literalism is meant to have an imaginative conviction more powerful than story telling, and animals contribute to this imaginative conviction in two quite distinctive ways. On the one hand, the modeling of the animals that Noah and his family transported is both lavish and minutely detailed. These include pairs of extinct animal kinds, ${ }^{10}$ such as caseids and pareiasaurs, along with surviving megafauna, such as bears,

10 "Kind" is the translation of the Hebrew min that is used throughout the Ark Encounter and its accompanying publications. A broader category than species, it may contain many different species. See Laura Welch, Inside Noah's Ark: Why It Worked (Green Forest, AZ: Master Books, 2016), I7: "Since Noah was only sent representatives from relevant kinds, all land-dwelling vertebrate species not present on the Ark were wiped out. Therefore, if we see an Ark kind represented today by different species-e.g., horses, zebras, and donkeys of the equid kind-those species have developed since the time of the Flood. Therefore, species are simply varying expressions of a particular kind." 
giraffes, and sloths. Both the facture of the animal bodies and their miseen-scène has been accomplished with remarkable care. Their hair, skin, and fur has a palpable plausibility, their poses are life-like, and the animals are installed in wooden cages with simulations of the sounds they would have made during the journey. A video display shows the work of making the animal bodies, with a particularly interesting testimony from one of the artists about the creation and installation of their eyes as what gives the final sense of veracity to the feeling of life they convey.

The other role that animals play at the Ark Encounter is as part of its disruption of the linkage between Noah's ark and child mindedness. A large bay in one of the exhibition decks contains a display of ark toys behind glass. Above the entry way, unrealistic plastic animals crowd around a sign that says "Fairy Tale Ark," while to the side of the vitrine containing dozens of toy arks from around the world, a red horned serpent coils around another sign that proclaims: "If I can convince you that the Flood was not real, then I can convince you that Heaven and Hell are not real." In the forefront of the vitrine that contains the assemblage of toys, a set of seven purpose-made books lays out the 7 D's of Deception, taking the whimsical and fanciful arks marketed to children to task for attacking the truthfulness of Scripture.

It is within this context of disavowal that the Ark Encounter poses the question about unicorns. One of its signboards asks: "Were there unicorns on the ark?" Its answer is philological: "unicorn" is a willful mistranslation of the Hebrew word for "wild ox" or "wild bull" that has been used to discredit the Genesis story, when rhinoceros might just as well have been used instead. The unicorns of the Ark are simply the representatives of the rhinoceros kind. The disavowal takes aim at one of the story's most reliable affordances- the possibility it offers for staging animal identification as a vanishing possibility of child mind that can be apprehended by the child itself. Dispelling melancholy about the species wiped out by the Flood goes hand in hand with rehabilitating the Flood as a proper subject for adult contemplation. Melancholy, the ground of poiesis, is the enemy of truth, and the Ark Encounter places great emphasis on the technoscience of ark building instead, which includes the study of animal behavior that must have preceded it to ensure its success, even suggesting that Noah and his family might have kept a collection of such observations on the Ark itself. 


\section{Lee Scratch Perry's Ark}

In Flight Ways, Thom van Dooren lets us look inside some arks of conservation biology, where we witness the enormous expense of labor and emotional capital involved in, for example, getting whooping cranes back on their abandoned migration routes. Not only is it unclear whether, or for how long, there will be any place for them to fly to, but instrumentalization of the lives of other animals - what van Dooren calls "violent-care"-is an integral part of the conservation effort. Captive populations of sandhill cranes serve as "sacrificial surrogates" for the preservation of the other species, unwittingly incubating whooping crane eggs, while individual whooping crane females are themselves the subject of forced insemination for conservation purposes.

When it comes time for the young whooping cranes to learn to fly, human volunteers must dress up in crane suits and pretend to be airplanes, so that the young birds will be acculturated to the ultralight aircraft that will eventually lead them on their way through the sky. van Dooren pushes back on the idea that what we witness here is a form of shared life, in which the cranes and their human mentors are co-creators of a co-evolved, and coevolving, form of becoming-animal. This is, after all, managed life-animal lives managed for the sake of the projected human good of a world that has whooping cranes in it. ${ }^{11}$ On the other hand, at the moment when the conservation project threatens to reify into an endeavor conducted for its own sake, a prolonged form of practice whose originally anticipated outcomefree cranes in the wild under their own direction-may never materialize, the ark becomes its own form of life, not merely a bridge between a vanished past and a projected future. This is when its sacrificial structure as a form of shared life becomes visible. Life is given for the sake of life, not always in a kind or careful or reflective way, but always as the claim that life makes on the living.

In a recent reflection on conservation efforts directed at the Hawaiian crow, extinct in the wild for over a decade, van Dooren explores the desire that fuels the construction of animal arks in relation to the question of species identity, conceived not in terms of genetic integrity, or the goal of establishing a viable population in a viable habitat, but rather as a question about what would constitute an authentic animal survival at the level of behavior. ${ }^{12}$

${ }^{11}$ Dooren, Flight Ways, 87-I 24.

${ }^{12}$ Thom van Dooren, "Authentic Crows: Identity, Captivity and Emergent Forms of Life," Theory, Culture \& Society 33, no. 2 (2016): 29-52. 
The desire van Dooren interrogates - that there should be an authentic way of being a crow that gets preserved along with crow bodies-can be productively compared with the idea of American Indian survivance articulated by Gerald Vizenor. Vizenor contrasts a spurious authenticity fabricated in accordance with the simulation of Indian culture produced by the colonial imaginary with the modes of partial identification constitutive of trickster performance. ${ }^{13}$ Thinking in these terms, trickster crows whose survivance is performed in a catastrophically fluid ecological present would afford an escape from the melancholy of loss and offer a realistic hope about what it would mean to want the continuing presence of endangered animals alongside us in the unknown world to come.

The idea that improvisation and performance are cheerily coded in contrast to the melancholy persistence of identity is interrogated in an old poem by Thom Gunn from the era of the first onset of AIDS and eighties homelessness:
Improvisation
I said our lives are improvisation and it sounded un-rigid, liberal, in short a good idea.
But that kind of thing is hard to keep up: guilty lest I gave to the good-looking only I decided to hand him a quarter whenever I saw him-what an ugly young man: wide face, round cracked lips, big forehead striped with greasy hairs. One day he said 'You always come through' and I do, I did, except that time he was having a tantrum hitting a woman, everyone moving away, I pretending not to see, ashamed.

\section{Mostly}

he perches on the ungiving sidewalk, shits behind bushes in the park, seldom weeps, sleeps bandaged against the cold, curled on himself like a wild creature, his agility of mind wholly employed with scrounging for cigarettes, drugs, drink

${ }^{13}$ Gerald Vizenor, Manifest Manners: Narratives on Postindian Survivance (Lincoln: University of Nebraska Press, I994), 76. 
or the price of Ding Dongs, with dodging knife-fights, with ducking cops and lunatics, his existence paved with specifics like an Imagist epic, the only discourse printed on shreds of newspaper, not one of which carries the word improvisation.

Gunn's critical suggestion is that what looks like improvisation from the perspective of a comfortable, if somewhat tedious, persistence of identity is in fact a chronic inability to establish the conditions of personhood in the absence of what is needed to sustain a human form of life. One need not subscribe to a normative idea of species being to believe that some minimal conditions must be met for any kind of animal to be happy in its own body. One of the most traumatic experiences of my life was watching beavers at the Lincoln Park Zoo in Chicago swimming to the end of their glass enclosure, scrabbling desperately at the invisible wall, then turning around and swimming back a few minutes later to reenact their failure to escape from the imprisonment imposed on them. This is what violent-care looks like. You can concentrate on the building of the ark itself and block out the suffering of those it is meant to carry forward towards their uncertain future, but the very fact of ark building is an acknowledgment that there is no place for the animals inside it to live as living beings that have a will to live as the animals that they are. This recognition does not involve imposing a telos on the lives that they are actually living, only the acknowledgment that another animal is unhappy in its body in the circumstances in which it has been placed.

The tide of extinction is just beginning to rise and we have no idea how long the flood will last. Melancholy seems like an entirely warranted response to this situation because melancholy is the affect of unhappy situations whose resolution is unforeseeable. Melancholy is the affect of ark building, and can either be acknowledged or disavowed as its efficient cause. Without a sense that the world ought to be better than it is, that it ought to provide a habitat in which the inhabitants of arks can do more than just survive as they do in the ark, there would be no reason to build the ark in the first place.

A standout exception to the generative relationship between melancholy and ark building is Lee Scratch Perry's Black Ark recording studio. Gerald Vizenor argues that the invention of the Indian is the needy fabrication of a melancholy civilization and that tricksterism is the opposite of its "obscure moral simulations" - the "wild ironies of survivance, transformation, natural 
reason, and liberation." ${ }^{14}$ Black Ark operated according to tricksterism's gestures of irony and partial identification. On the one hand, it was conceived as "an antidote to the Caucasian myth of Noah's Ark," and symbolically likened to the Ark of the Covenant by way of contrast, so that it might be a sanctuary for black Rastafarians, and "a place where joyful music could be made unto the Lord on unmitigated terms." ${ }^{15}$ But Perry also conflated Noah's Ark and the Ark of the Covenant:

Black Ark studio, its original base is on the righteousness of fulfillment of biblical prophecy, the Ark of the Covenant which Noah, who gain blessing and favour of the Lord to produce the mind of people who are clean, to produce and portrayeth life's positive dreams, to make it a reality, so the reason to call my studio the Black Ark, it means originally the Ark of the Covenant in ... not interpreting but performing the works of the Holy Trinity of Love that firmament over our head above. ${ }^{16}$

Perry himself, who his collaborators called the "Noah of the Ark,"17 embraced a divided mind that his critics have wanted to clear up. His suspension of the difference between the Ark of the Covenant and Noah's Ark is a refusal to use metaphor for the sake of definition and derealization-definition as derealization, in Empson's sense. For Black Ark was underway in ways he did not wish to pin down:

It was like a space craft. You could hear space in the tracks. Something there was like a holy vibration and a godly sensation. Modern studios, they have a different set-up. They set up a business and a money-making concern. I set up like an ark ... You have to be the Ark to save the animals and nature and music. $^{18}$

Black Ark featured a pond for water birds in the drum booth because "birds are the power of the air." 19 The studio was famously low-tech and

${ }^{14}$ Vizenor, Manifest Manners, 76.

${ }^{15}$ David Katz, People Funny Boy: The Genius of Lee "Scratch" Perry (London: Omnibus Press, 2006), I77-78.

${ }^{16}$ Perry, in ibid., 178.

${ }^{17}$ Ibid., 282.

${ }^{18}$ Perry, in David Toop, Ocean of Sound: Aether Talk, Ambient Sound and Imaginary Worlds (London: Serpent's Tail Press, 200I), I I 4.

${ }^{19}$ Katz, People Funny Boy, 332. 
(unlike Noah's Ark) pervious to the outside. Its generativity was a function of its disavowal of the basic premise of keeping unwanted sound out (unwanted because unanticipated), which is fundamental to the functioning of any normal studio, just as keeping what's wanted in, and what's unwanted out, is basic to the functioning of an animal ark. ${ }^{20}$ For Perry, becoming the ark is the opposite of building the ark in so far as it values putting your own life into the machine over making the machine serve, furnish, or express your desires:

I see the studio must be like a living thing, a life itself. The machine must be live and intelligent. Then I put my mind into the machine and the machine perform reality. Invisible thought waves-you put them into the machine by sending them through the controls and the knobs or you jack it into the jack panel. The jack panel is the brain itself, so you got to patch up the brain and make the brain a living man, that the brain can take what you sending into it and live. ${ }^{21}$

Shared life has a sacrificial structure here, and while it is true that in other arks, too, life is given for the sake of life, Perry abandons the self-realization in sacrifice by giving his work over to animals, machines, the weather, organismic processes, and even matter itself as the form of his ark building. The desire that there be an ark is given up for adoption while it is still a work in progress. There is still the desire to cherish life, but "you have to be the Ark to save the animals and nature and music" means giving up the you that is the

${ }^{20}$ Despite its supercilious tone, https://en.wikipedia.org/wiki/Black_Ark_Studios has a useful summary of Perry's recording practices in this regard: "Perry once buried microphones at the base of a palm tree and thumped it rhythmically to produce a mystifying bass drum effect and his drum booth at the Black Ark was for a time surrounded with chicken wire to further his distinctive sound. Many of his songs are layered with a variety of subtle effects created from broken glass, ghastly sighs and screeches, crying babies, falling rain and cow noises ... He would often "bless" his recording equipment with mystical invocations, blow ganja smoke onto his tapes while recording, bury unprotected tapes in the soil outside of his studio, and surround himself with burning candles and incense, whose wax and dust remnants were allowed to infest his electronic recording equipment. He would also spray tapes with a variety of fluids, including urine, blood and whisky, ostensibly to enhance their spiritual properties. Later commentators have drawn a direct relationship between the decay of Perry's facility and the unique sounds he was able to create from his studio equipment." The Ark Encounter devotes a number of admittedly speculative signboards to the question of how animal and human waste was disposed of on the Ark.

${ }^{21}$ Perry, in https://en.wikipedia.org/wiki/Black_Ark_Studios. 
subject of the desire so as to enable the coming into being of the desire itself. Among the omnipresent instantiations of sacrificial thinking, Perry's stands out because it is neither self nor other that is sacrificed here, but the very idea of a new order that is to be reached or realized though sacrifice-the coming to an end in a future good that justifies sacrificial violence in the present. ${ }^{22}$ The structure of giving one thing for the sake of another is given over with the abandonment of the ontological idea of self-realization in making.

Perry's practice is more fully sacrificial than improvisation, letting-be, or sympoiesis, because it involves a far greater devolution of outcomes to the other. The ark comes into being only by abandoning the will to engineer its success. The risks are enormous and the willingness to roll the dice is commensurate with them. On the other hand, Perry's is the only ark I have encountered that is conceived under the sign of joy. Every ark must strike a balance between the desire for free relationality with its cargo of the living, and the reification of what the lives of the living amounts to. To preserve toads we must have some idea of toadness in general that makes us think their lives are worth preserving, and this reification and knowing in advance are at odds with the projection of a future life in which we will relate to them more freely than we can as providers of an ark builder's managed care. This is why we need Black Ark to float alongside the other arks, to remind us of what we hope that future will be like.

${ }^{22}$ Hugo Reinert, "Sacrifice," Environmental Humanities 7, no. I (2016): 255-58. 